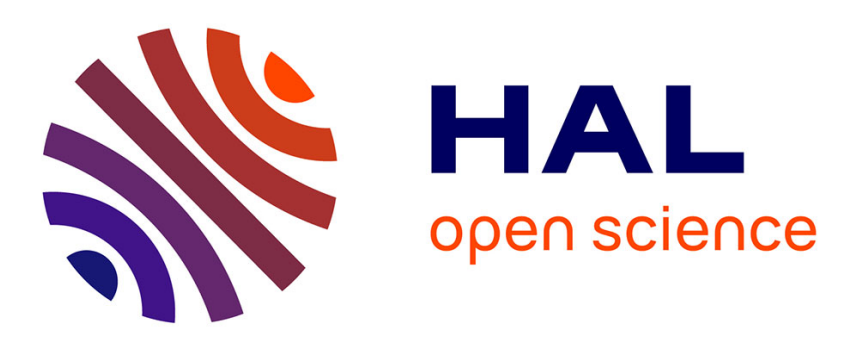

\title{
Adaptation towards Reference Values: A Non-linear Perspective
}

Yannis Georgellis, Andros Gregoriou, Nikolaos Tsitsianis

\section{To cite this version:}

Yannis Georgellis, Andros Gregoriou, Nikolaos Tsitsianis. Adaptation towards Reference Values: A Non-linear Perspective. Journal of Economic Behavior and Organization, 2008, 67 (3-4), pp.768. 10.1016/j.jebo.2007.08.007 . hal-00614678

\section{HAL Id: hal-00614678 https://hal.science/hal-00614678}

Submitted on 15 Aug 2011

HAL is a multi-disciplinary open access archive for the deposit and dissemination of scientific research documents, whether they are published or not. The documents may come from teaching and research institutions in France or abroad, or from public or private research centers.
L'archive ouverte pluridisciplinaire HAL, est destinée au dépôt et à la diffusion de documents scientifiques de niveau recherche, publiés ou non, émanant des établissements d'enseignement et de recherche français ou étrangers, des laboratoires publics ou privés. 


\section{Accepted Manuscript}

Title: Adaptation towards Reference Values: A Non-linear

Perspective

Authors: Yannis Georgellis, Andros Gregoriou, Nikolaos

Tsitsianis

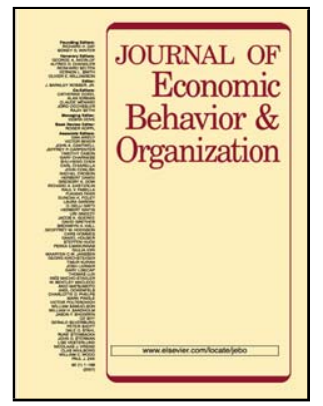

PII:

S0167-2681(07)00171-0

DOI:

doi:10.1016/j.jebo.2007.08.007

Reference:

JEBO 2143

To appear in: Journal of Economic Behavior \& Organization

Received date: $\quad 9-3-2006$

Revised date: $\quad 28-8-2007$

Accepted date: $\quad$ 29-8-2007

Please cite this article as: Georgellis, Y., Gregoriou, A., Tsitsianis, N., Adaptation towards Reference Values: A Non-linear Perspective, Journal of Economic Behavior and Organization (2007), doi:10.1016/j.jebo.2007.08.007

This is a PDF file of an unedited manuscript that has been accepted for publication. As a service to our customers we are providing this early version of the manuscript. The manuscript will undergo copyediting, typesetting, and review of the resulting proof before it is published in its final form. Please note that during the production process errors may be discovered which could affect the content, and all legal disclaimers that apply to the journal pertain. 


\title{
Adaptation towards Reference Values: A Non-linear Perspective
}

\author{
Yannis Georgellis \\ Brunel University \\ Andros Gregoriou \\ Brunel University \\ Nikolaos Tsitsianis \\ University of Hertfordshire
}

\begin{abstract}
Using large-scale panel data, we examine the dynamics of adjustment towards reference points for key workplace attributes. We discover that an Exponential Smooth Transition Autoregressive (ESTAR) model is superior to a linear model in characterizing such a process. The speed of adjustment increases nonlinearly with the distance from reference points and adjustment is faster for job satisfaction shocks compared to shocks in earnings or work hours. Our findings lend further credence to the relative utility hypothesis and highlight the inherently nonlinear nature of the dynamic path of adjustment towards reference points, a previously neglected issue in the adaptation literature.
\end{abstract}

JEL Classification: D60, I31, J60, C20

Keywords: Reference Points, Relative Utility, Adaptation, ESTAR Models, Job Satisfaction

Acknowledgements: We are grateful to Andrew Clark, Richard Easterlin, Peter Sanfey, the editor of this journal and two anonymous referees for helpful comments and suggestions. Comments by participants at the Seventh International GSOEP User Conference are also gratefully acknowledged.

Corresponding author: Yannis Georgellis, Economics and Finance, Brunel University, Uxbridge, Middlesex UB8 3PH, United Kingdom. Tel: +(44)-1895-266635; Fax: +(44)-1895-472851

E-mail: yannis.georgellis@brunel.ac.uk 


\section{Adaptation towards Reference Values: A Non-linear Perspective}

\section{Introduction}

The notion that utility is relative in nature continues to gain a wider acceptance among economists and to be supported by a growing number of empirical studies. ${ }^{1}$ Clark and Oswald (1996), for example, show that utility depends on income relative to some reference or comparison income, while Easterlin (2001) advocates that earnings expectations should be explicitly introduced in a utility function. In the same vein, Stutzer (2004) finds that higher income aspirations, determined both by individuals' past income and the average income in their community, reduce utility, a conclusion also supported by the findings of Ferrer-i-Carbonell (2005) who shows that income of the reference group is as important as one's own income for individuals' happiness. ${ }^{2}$

Recent work on adaptation further highlights the importance of reference points in determining actual behavior in that a divergence between individuals' current status and their aspiration or reference level causes disutility that could spur them into action to change their current status. For example, Rizzo and Zeckhauser (2003) find that physicians take strong, often unappealing actions to boost their earnings when they experience shortfalls from their reference income. Strikingly, for physicians who are at or above their reference income, reference income does not seem to influence future income growth. In a different context, Fiegenbaum et al. (1995) also reaffirm the prediction that the risk behavior of individuals depends on both their reference point and their current situation. Individuals who believe that their current state is below their reference point tend to exhibit risk-seeking behavior, while individuals who believe that their current state is above their reference point exhibit risk-averse behavior.

\footnotetext{
${ }^{1}$ This trend follows the publication of the Kahneman and Tversky (1979) article on prospect theory, which according to the 2002 Nobel Prize committee, is the most cited paper ever published in Econometrica.

${ }^{2}$ Van de Stadt et al. (1985) offer some of the earlier evidence consistent with the relative utility hypothesis, although they acknowledge the possibility that utility might be partly absolute. Other notable studies supporting the relative utility hypothesis include Clark (2000) and Solberg et al. (2002).
} 
Although psychological theories of adaptation, often encapsulated in the set point or baseline model, examine how departures from reference points affect individuals' utility, there is little empirical evidence on the dynamics of the adaptation process. The set point model postulates that people react to or are affected psychologically by events, but they eventually adapt back to their baseline level of well-being. This baseline level is essentially a reference point determined by individuals' past, pre-event experience, or by individuals' standing relative to others, "people like you". Brickman et al. (1978), Headey and Wearing (1989), and Lykken and Tellegen (1996), among others, provide strong supporting evidence for the set point theory, concluding that adaptation is usually quick and complete. ${ }^{3}$ The study by Lucas et al. (2003) is one of the first to support the set point theory using large-scale panel data, thus overcoming some of the limitations of earlier empirical work. However, more rigorous testing of adaptation theories and the dynamics of adjustment towards reference points is still in its infancy.

In this paper, we use data from the German Socio-Economic Panel (GSOEP), a large-scale panel survey, to examine the dynamics of the adjustment process towards reference values for key workplace characteristics. ${ }^{4}$ Focusing on earnings, hours of work, and overall job satisfaction, three factors often quoted as important determinants of labor market behavior, we model the dynamics of adjustment as a non-linear process. More specifically, we fit an Exponential Smooth Transition Autoregressive (ESTAR) model, which we find to be superior to a linear model in characterizing the path of adjustment towards reference points. The estimated ESTAR coefficients imply that the speed of adjustment increases in a non-linear fashion with the distance from reference points. Further comparisons across the three main job attributes under consideration reveal that a one

\footnotetext{
3 Van Praag (1971) and Van Praag and Kapteyn (1973) were the first, among economists to explore the 'preference drift' phenomenon, which refers to the same mechanism that Brickman and Campbell (1971) termed 'hedonic treadmill'. In recent years, economists have embraced adaptation as an important issue that could further our understanding of economic behavior. Recent evidence by Easterlin (2005) suggests that there is a clear distinction to be made between adaptation in the economic domain and adaptation in the life domain. Easterlin finds that aspirations about economic wealth and other pecuniary aspects of one's well-being tend to change with the level of actual circumstances, suggesting almost complete adaptation, but this is not the case with marriage, number of children and other non-pecuniary aspects of one's life. In another study, Dunn (1996) uses data on income and leisure tradeoffs and finds evidence of adaptation in the labor market. Van Praag et al. (2003) explore the link between general well-being and well-being in various domains, including health, financial situation, job, leisure, housing, and environment, thus providing a broader context for the study of adaptation.
} 
standard deviation change in job satisfaction results in a much higher speed of adjustment towards reference values and a higher probability of job switching than a one standard deviation change in wages or work hours. Gender differences in the adjustment process towards reference values are also apparent. Although shocks in wages and working hours seem to be equally important in terms of the speed of adjustment towards reference points for both men and women, we find that, compared to men, the speed of adjustment towards reference wages and hours is lower for women. Most interestingly, our results show that an asymmetry in the adjustment process towards reference values exists depending on whether actual values are above or below their reference values. While our results support the hypothesis of a non-linear adjustment when actual values are below the reference values, there is no adjustment at all, linear or non-linear, when actual values are above their reference values.

The remainder of the paper is structured as follows. Section 2 describes the GSOEP sample and outlines the empirical methodology. Section 3 presents the main results, and section 4 concludes.

\section{Data and Methodology}

\subsection{Data}

We use data from the first 19 waves of the German Socio-Economic Panel (GSOEP) for the period 1984-2002. The GSOEP is a nationally representative panel data set of individuals and households residing in the old and new federal German states. The original sample in 1984 was selected following a stratified random sampling procedure, and the panel is periodically refreshed with new samples so that successive waves are representative of the relevant population in Germany. In

\footnotetext{
${ }^{4}$ As a referee pointed out, there is a subtle distinction to be made between the use of the terms adaptation and adjustment. Although adaptation usually refers to the formation of preferences / reference points, our emphasis in this paper is on the adjustment process towards reference points.
} 
2002, there were approximately 12,000 households and 22,000 persons in the panel. ${ }^{5}$ The dataset provides detailed information on personal and labor market characteristics, including information on the three main variables of interest: labor earnings, work hours and job satisfaction. ${ }^{6}$

To provide a context for our empirical analysis, it is worth noting that during the period 1984-2002 there has been a real increase in average earnings, accompanied by a remarkable increase in the gap between the mean and median values and the dispersion of the earnings distribution. This is indicative of an increase in the proportion of people in the lowest quartile, explained by the slowdown of the German economy and rising unemployment rates. In terms of reported job satisfaction, there is a downward trend in Germany in the 1990s, for both men and women. This downward trend in job satisfaction is also confirmed independently in the ISSP series: the proportion of workers completely or very satisfied with their job was 39 percent in 1997 , down from 44 percent in 1989. Finally, there is an increase in the number of workers who are not satisfied with the work hours, with an increasing preponderance of both male and female workers who wish to work fewer hours, and from a smaller base an increase in the proportion wishing to work more hours.

\subsection{Methodology}

For our empirical analysis, we limit the sample to include only West German workers who are between 18 and 65 years of age and working full-time in either the public or private sectors. Excluding the self-employed and those in training results in a sample of 49,177 and 20,903 personyear observations for males and females. We track workers in this sample up to the point when job switching occurs, that is, when workers' full-time spell with their current employer is terminated followed by an employment spell with a new employer. The main aim of our empirical

\footnotetext{
${ }^{5}$ For a detailed description of the GSOEP data see Burkhauser et al. (2001).

${ }^{6}$ Job satisfaction is an ordinal variable, based on respondents' answers to the following question: "How satisfied are you today with the following areas of your life? Please answer by using the following scale, in which 0 means totally unhappy and 10 means totally happy. If you are partly happy and partly not, select a number in between". Desired hours of work are based on responses to the question: "If you could choose the extent of your hours at work, taking into account that your earnings would change corresponding to the time: How many hours per week would you like to work."
} 
methodology is to quantify the gap between actual and reference values and how such a gap affects the speed of adjustment towards reference values.

Let $e_{t}$ be the gap between an individual's actual state $h_{t}$ and her reference point $h_{t}^{*}$

$$
e_{t}=h_{t}^{*}-h_{t}
$$

As the reference values $h_{t}^{*}$ for earnings and job satisfaction are not directly observed in the data, before examining the dynamics of adjustment of $h_{t}$ towards $h_{t}^{*}$, we need reasonable proxies for $h_{t}^{*}$, which requires an operational definition of the reference group. Our measures of reference earnings and job satisfaction are based on the fitted values from earnings and job satisfaction regressions, similar to the approach used by Clark and Oswald for estimating comparison income. For hours of work we use individuals' responses about desired hours of work as reported in the GSOEP data. ${ }^{7}$

Using the above proxies for workers' reference values, we then explore the dynamics of adjustment towards these reference values, adopting the methodology by Granger and Terasvirta (1993) and Terasvirta (1994) on the Smooth Transition Autoregressive (STAR) model. Although alternative non-linear models could be considered, we adopt the STAR methodology because it allows for the speed of adjustment to vary in a non-linear fashion with the distance between actual and reference values. Moreover, STAR models imply a smooth non-linear adjustment process, as opposed to Markov switching type of models that assume that adjustment occurs instantly from one state to another. ${ }^{8}$ Before adopting the STAR model as the preferred model for capturing the dynamics of adjustment of actual to reference values, we perform a three-stage testing procedure for the presence of non-linearities. First, we specify the appropriate lag length for the linear

\footnotetext{
7 Other studies on reference groups include Easterlin (1995), who implicitly assumes that individuals compare themselves with all the other citizens of the same country, and Persky and Tam (1990), who assume that the reference group consists of all individuals living in the same region. Ferrer-i-Carbonell defines the reference group to include all people with similar educational level, same age bracket and living in the same region, while McBride (2001) uses the average values of all those in the same age group within 5 years younger or older than the individual concerned. In an earlier study, Van de Stadt et al. define the reference group according to education level, age and employment status.
} 
autoregressive model. Second, having determined the optimum lag length, we test for the presence of non-linearities. If non-linearities are present, then at the third stage we test whether the Logistic STAR (LSTAR) or the Exponential STAR (ESTAR) model can better describe the dynamic adjustment process.

Formally, consider two possible regimes comprising a pure 'small' and pure 'large' adjustment of individuals' current status with respect to changes in their reference points. ${ }^{9}$ Following Granger and Terasvirta, we write a STAR model of order $k$, for $e_{t}$ as

$$
e_{t}=\theta_{0}+\theta_{1}{ }^{\prime} x_{t}+\left(\delta_{0}+\delta_{1}{ }^{\prime} x_{t}\right) F\left(e_{t-d}\right)+w_{t}
$$

where $x_{t}=\left(e_{t-1}, e_{t-2}, \ldots e_{t-k}\right), \theta_{1}=\left(\theta_{1}, \theta_{2}, \ldots \theta_{k}\right)^{\prime}, \delta_{1}=\left(\delta_{1}, \delta_{2}, \ldots \delta_{k}\right)^{\prime}, w_{t} \sim i i d\left(0, \sigma^{2}\right), F($.

is the continuous transition function, $e_{t-d}$ is the switching variable, and $d$ is the delay parameter. $F($.$) is a monotonically increasing function with F(-)=0$ and $F()=1$, which yields a non-linear asymmetric adjustment.

Consider the following LSTAR function

$$
F\left(e_{t-d}\right)=\left\{1+\exp \left[-a\left(e_{t-d}-c\right)\right]\right\}^{-1}
$$

where $a$ measures the smoothness of transition from one regime to another and $c$ is a threshold value for $e$ that indicates the halfway point between the two regimes.

The LSTAR model assumes that different regimes may have different dynamics and that adjustment takes place in every period, but the smoothness of adjustment varies with the extent of

\footnotetext{
${ }^{8}$ The main alternative non-linear formulation to the STAR models is the Markov Switching Regime Model, first established by Hamilton (1989). Markov switching models are popular in the finance literature where high frequency stock price data is used to explore second-by-second adaptation in financial markets.

${ }^{9}$ The ESTAR model is essentially a dynamic gap model, allowing for both the actual and reference values of the variables of interest to change overtime.
} 
the deviation from equilibrium. The transition function of LSTAR increases monotonically in $e_{t-d}$ and yields asymmetric adjustment towards equilibrium in the model. Moreover, $F(.) \rightarrow 0$ as $e_{t-d} \rightarrow-\propto$ and $F(.) \rightarrow 1$ as $e_{t-d} \rightarrow+\propto$; thus $F($.$) is bounded between 0$ and 1 where $F()=$.0.5 if $e_{t-d}=c$. The smaller is $a$, the smoother the transition. In the extreme, $a=0$ means that $F($.$) becomes a constant, so (2) becomes a linear model. On the other hand, as a \rightarrow \infty$ there is an even sharper transition at $e_{t-d}=c$ where $F($.$) jumps from 0$ to 1 .

Terasvirta and Anderson (1992) define the Exponential STAR (ESTAR) function as:

$$
F\left(e_{t-d}\right)=1-\exp \left[-a\left(e_{t-d}-c\right)^{2}\right]
$$

where, as previously, a measures the speed of transition from one regime to another and $c$ is some threshold value for $e$ that indicates the halfway point between the two regimes. The ESTAR function in (4) defines a transition function about $c$ where $F($.$) is still bounded between 0$ and 1. As in the case of the LSTAR model above, the main property of the ESTAR model, described in equation (4), that makes it an attractive model in the present context is the fact that it captures the non-linear, smooth adjustment process towards reference values.

The initial testing for the presence of non-linearities in $e_{t}$ involves three stages. First, a linear autoregressive model for $e$ is specified in order to determine the lag length $k$. The lag length selection is based on the Schwarz information criteria and the Ljung-Box statistic for serial correlation. The residuals are saved from the chosen autoregressive model and denoted as $v$. Second, having determined $k$, the next stage is to test for the presence of non-linearities. This is done through the estimation of

$$
v_{t}=\beta_{0}+\beta_{1}{ }^{\prime} x_{t}+\beta_{2}{ }^{\prime} x_{t} e_{t-d}+\beta_{3}{ }^{\prime} x_{t} e^{2}{ }_{t-d}+\beta_{4}{ }^{\prime} x_{t} e^{3}{ }_{t-d}+w_{t}
$$


where the linearity test is on the null hypothesis $H_{0}: \beta_{2}{ }^{\prime}=\beta_{3}{ }^{\prime}=\beta_{4}{ }^{\prime}=0$. Equation (5) is estimated across a range of values for $d$ where the smallest $p$-value attached to the linearity test determines $d$ in the estimation of (2). The final stage of the non-linearity test is to determine which smooth transition model, LSTAR or ESTAR, is appropriate for the data. This is done by running the following sequence of nested tests:

$H_{04}: \beta_{4}{ }^{\prime}=0$

$H_{03}: \beta_{3}{ }^{\prime}=0 / \beta_{4}{ }^{\prime}=0$

$H_{02}: \beta_{2}{ }^{\prime}=0 / \beta_{4}{ }^{\prime}=\beta_{3}{ }^{\prime}=0$

The ESTAR model does not contain a cubic term (see equation 3.16 in Terasvirta). Therefore, if we reject (6) there is a cubic term in the non-linear model suggesting that we have an LSTAR specification. If we accept (6) and reject (7), then the non-linear model possess a squared term but not a cubic term. Since a squared term is required for an ESTAR specification and we have no cubic term, then we can conclude that accepting (6) and rejecting (7) implies acceptance of the ESTAR model (see equation 3.16 in Terasvirta). Accepting (6) and (7) and rejecting (8) leads to an LSTAR model because although $H_{02}: \beta_{2}{ }^{\prime} \neq 0$ is important for an LSTAR specification, it is insignificant for an ESTAR model (see page 209, equation 3.10 in Terasvirta). However, Granger and Terasvirta (1993) and Terasvirta (1994) show that application of this sequence of tests may lead to incorrect conclusions because the higher order terms of the Taylor expansion used in deriving these tests are disregarded. Thus, they recommend that the choice of STAR model should be made on the basis of the lowest $p$-value among the values computed for all the F tests of (6)-(8).

To account for potential asymmetries in the adjustment process, we implement the STAR methodology separately when actual values are below reference values and when actual values are above reference values. When actual values are above reference values, the model does not reject 
the null hypothesis of no non-linear adjustment. In this case, a further test of the null hypothesis $H_{o}$ : $\beta_{1}=0$ for the presence of linear adjustment shows no adjustment at all. Therefore, all subsequent results reported in the empirical section focus on non-linear adaptation of earnings, job satisfaction and work hours when actual values are below reference values. ${ }^{10}$

\section{Empirical results}

\subsection{Reference values}

In the first stage of our empirical analysis, we construct reference values for earnings and job satisfaction based on the estimated coefficients of standard earnings and job satisfaction equations respectively. ${ }^{11}$ These results are shown in Tables A1 and A2 in the appendix, and they are broadly consistent with the findings of previous studies. Briefly, as the results in Table A1 suggest, both males and females earnings are higher for those with longer job tenure, those in higher level occupations and for skilled workers, and those working in larger firms. A high secondary degree followed by apprenticeship seems to yield, ceteris paribus, a positive and significant return for men. Age seems to have a positive, non-monotonic effect on earnings, while the effect of marriage is stronger for men than that for women. As expected, health limitations have a negative effect on earnings.

The results in Table A2 reveal that earnings have a positive effect on job satisfaction, while reference earnings have a negative effect. ${ }^{12}$ Preferences for work hours are important determinants of job satisfaction, consistent with the findings of previous studies. ${ }^{13}$ Although marriage has a

\footnotetext{
${ }^{10}$ The results of linear and non-linear tests for the case of actual values above the reference values are available upon request.

${ }_{11}^{11}$ Estimated using a panel fixed effects estimator. A Hausman test rejected the random effects specification.

12 The additional list of variables included in the earnings equation and not included in the job satisfaction equations help to identify the model. A number of alternative specifications of the earnings and job satisfaction equations produce very similar results, but the specifications in Tables A1 and A2 dominate, based on standard log-likelihood comparisons among alternative specifications.

${ }^{13}$ For example, Green and Tsitsianis (2005) find that working more hours than the desired level lowers job satisfaction for men by an average of 0.34. Interestingly, Clark (2005) summarizes evidence in OECD countries, showing that overall job satisfaction is either stable or declining despite rising wages and falling hours of work.
} 
positive effect on men's job satisfaction, it has a negative effect for women. Consistent with the findings of Clark et al. (1996), job satisfaction increases with age, but in a non-linear fashion.

Figures 1-3 illustrate how actual and reference values for earnings, job satisfaction and work hours evolve over time. As Figure 1 illustrates, reference earnings for both males and females tend to follow actual earnings, in broad agreement with Easterlin's (2005) claim that reference or aspiration income tends to increase proportionately with individuals' actual income. In Figure 2, reference values for job satisfaction fluctuate between 7 and 8 , consistent with the findings of Ferrel-i-Carbonell who predicts job satisfaction in the same range for West Germans. Interestingly, Figure 2 reveals a slight downward trend in job satisfaction for both males and females, with reference values to follow this trend. It is worth noting that the particular value of job satisfaction data lies in its trends. If it can be assumed that the norms against which job satisfaction judgments are made are stable in the medium term, the trend data then convey information about changes in well being. If job satisfaction is rising (falling) we could conclude that workers' well being is rising (falling), conditional on the assumption that their norms are changing a little or not at all. The same assumption can be made using the interpretation of job satisfaction adopted by Levy-Garboua and Montmarquette (2004). Whether this assumption is valid depends on the circumstances, which partly depend on the time horizon. Taken over the very long-term, this assumption may be dubious, but over the medium term, within a decade or so, it may be reasonable to assume comparatively stable norms.

\section{[Figures 1, 2 and 3 about here]}

Figure 3 summarizes the trend in actual and reference values for hours. It is evident that, for both males and females, actual hours are consistently above the reference values for the whole period under consideration. An obvious explanation might be that workers are obliged to work more than they wish because of structural and institutional constraints. Numerous studies in the economics 
literature focus on labor demand as a main factor restricting workers' income-leisure choices (Altonji and Paxson 1992, Kahn and Lang 1995, Hamermesh and Pfann 1996, Euwals and Van Soest 1999). However, one would expect that this explanation is less relevant in contemporary labor markets where part-time work, flexibility and family friendly work schedules become increasingly more important aspects of the workplace. Alternative explanations why workers' actual hours exceed their desired hours are based on social rationality arguments and goal-framing effects (Lindenberg 2001). Such explanations are based on the premise that workers are unlikely to view work simply as a choice between income and leisure, resulting in a deviation between actual and preferred hours. A similar explanation emphasizes the dynamics of the post-Fordist workplace environment that promotes over-employment as workers increasingly focus more on finishing tasks and less on income-leisure tradeoffs.

\subsection{Tests For Linearity and STAR Model Selection}

The application and estimation of the STAR models require stationary time series. Indeed, univariate $\mathrm{ADF}$ panel unit root tests on $e_{t}$ reject the null of non-stationarity at all levels of significance. ${ }^{14}$ For this reason, we proceed to apply the linearity tests and the STAR models to $e_{t}$.

Table 1 displays the results for the non- linearity tests for $e_{t}$. The linearity test is a variabledeletion $F$-test on the restriction applied to equation (5). $P$-values correspond to the test $H_{0}$ where the null is linearity. It should be noted that the Schwartz criterion is used to determine the lag length $k$ of the autoregressive process. Having determined $k$, a range of delay parameters $(1 \leq d$ $\leq 8$ ) was employed, choosing the value of $d$ with the lowest $p$-value of the linearity test. $Q(1)$ refers to the $p$-value associated with the Ljung-Box $Q$ statistic for serial correlation among the residuals. ${ }^{15}$ The Ljung-Box statistic suggests white noise residuals for all autoregressive models. Using 0.05 as

\footnotetext{
${ }^{14}$ The unit root tests indicate that $e_{t}$ is clearly stationary at all significance levels. For each test, the lag length is chosen using the Schwartz Bayesian Information Criterion. The results (not reported) are available upon request.

${ }^{15}$ The Ljung-Box statistic reports the correlogram of the residuals of the model. The null hypothesis is that the residuals are white noise. If the $p$-value is greater then 0.05 , then there is no serial correlation present in the residuals.
} 
a threshold $p$-value, the test rejects linearity, classifying the series as non-linear. We can therefore proceed to build non-linear models for $e_{t}$.

\section{[TABLE 1 about here]}

The tests for the choice between LSTAR and ESTAR models are shown in Table 2. Using the hypothesis tests outlined in equations (6)-(8), the results indicate that the ESTAR model is the most appropriate non-linear model in all cases. The ESTAR model implies that individuals' adjust their status of employment from high to low levels towards the middle ground in a similar fashion.

\section{[TABLE 2 about here]}

\subsection{Estimates of the non-linear models}

The ESTAR models are estimated by non-linear least squares, using the Marquandt algorithm. Granger and Terasvirta (1993, pp. 123-124) and Terasvirta (1994) point out that estimation of the parameter a may cause particular problems such as "overestimation". As Terasvirta explains, if $\mathrm{F}($.$) is not rescaled, then estimation results in very large values for \mathrm{F}($.$) , given that it is obtained$ from the solution of an exponential function. The problem of very large values for $\mathrm{F}($.$) is threefold.$ First, the non-linear adjustment of the model is overestimated. Second, the non-linear model does not converge as easily. Third, the standard errors of the non-linear model are very large resulting in poor estimation. Therefore, in order to achieve convergence and obtain reasonable and reliable estimates, we scale the argument of the transition function $\mathrm{F}($.$) by dividing it by \sigma^{2}(e)$. Hence, the scaled transition function used in the estimation of the ESTAR model is

$$
F\left(e_{t-d}\right)=\left[1+\exp \left\{-a\left(1 / \sigma^{2}(e)\right)\left(e_{t-d}-c\right)^{2}\right\}\right]
$$


Because of this scaling, we have used $a=1$ as an initial value and the sample mean as a starting value for the parameter c. ${ }^{16}$ The estimates of the autoregressive model are used as initial values for the $\theta$ and $\delta$ parameters.

\section{[TABLE 3 about here]}

Table 3 represents the non-linear estimation of equation (2) by the Gauss Newton method. The standard errors of the non-linear models are smaller then the standard errors of the linear models for all the series, suggesting that the non-linear models provide a better fit of the data. The Jacque Bera normality test indicates that the residuals are normally distributed for all the series examined. Hence, the non-linearities in individuals' job satisfaction, wages and work hours are not the outcome of any outliers in the data. We further test the residuals for first order serial correlation and ARCH effects. The p-values (using 0.05 as the threshold) reject the presence of serial correlation and the presence of ARCH non-linearity in the residuals for all series. In all cases $a$ is correctly signed and significantly different from zero at the 5 per cent level. This implies that individuals' have a faster speed of adjustment the further they are away from their reference points, thus justifying the use of the non-linear model.

It is also apparent from the examination of the ESTAR model estimates that the estimated $a$ values vary. Small values of $a$ are indicative of a very slow and smooth transition from one state to another. On the other hand, larger values of $a$ imply sharper and more abrupt changing of states. The results suggest that first, males are more inclined to change status faster than females given their larger values of $a$ with reference to working hours, wages and job satisfaction. This is consistent with the findings in previous studies pointing to differences in how such job attributes affect men's and women's labor turnover decisions (see, for example, Clark 1997). Second, both males and females have a quicker speed of adjustment with changes to job satisfaction than changes

\footnotetext{
${ }^{16}$ The scaling of $\left(e_{t-d}-c\right)$ in the transition function makes it possible to judge the size of $a$ (Granger and Terasvirta, pp 123,
} 
in wages and working hours. Table 3 also reports estimates of the halfway points, c, or thresholds between the two pure regimes. In all cases $c$ was insignificantly different from the mean adjustment rate, $\bar{e}$, implying that observations are distributed roughly equally between the left-hand and righthand tails of their respective exponential functions.

To gain further insight on what the estimated values of $a$ actually mean, we summarize individuals' adaptation propensities as a result of a one standard deviation shock to job satisfaction, working hours and earnings. Let $F\left(e_{t-d}\right)=0$ and $F\left(e_{t-d}\right)=1$ be the probabilities of individuals changing their current status. Suppose that we are initially in equilibrium with equal weights attached to the two pure regimes, implying that individuals have a $50 \%$ chance of changing status. Based on the estimated values for $c$ and $a$, in Table 3 , in the case of job satisfaction for males, a one standard deviation shock to $e_{t-d}$ yields $F\left(e_{t-d}\right)=0.71$. The corresponding values for male earnings and hours of work are 0.68 and 0.67 , suggesting that, for men, the speed of adaptation to job satisfaction shocks dominates the speed of adaptation to wages and hours of work shocks. Such a result is consistent and reinforces the view that job satisfaction has emerged in recent years as one of the main determinants of labor market behavior and quits in particular. Inspired by earlier work by Freeman (1978) and Akerlof et al. (1988) who used US data, Clark et al. (1998) and Clark (2001) use German and British data respectively to explore the link between job satisfaction and workers' quit behavior. Both studies find that even after controlling for wages and other job and personal characteristics, job satisfaction remains a robust predictor of quitting behavior. As Clark (2001) argues, job satisfaction seems to be a suitable index of a poor job match: people with low job satisfaction are significantly more likely to quit their jobs in the future than otherwise identical persons with high job satisfaction.

A similar story emerges for women, with estimated values for $F\left(e_{t-d}\right)$ of $0.58,0.50$ and 0.50 for a one standard deviation shock in job satisfaction, earnings and hours respectively. The estimated probabilities suggest that the speed of adjustment towards reference values for women is

153) and to interpret the estimated parameters of the ESTAR model as elasticities. 
generally lower than that for men for all three attributes under consideration. There is ample evidence in the existing literature that women tend to report higher levels of job satisfaction despite experiencing apparently worse objective job conditions. A proposed explanation relies on expectations. If job outcomes are evaluated relative to expectations, women's higher job satisfaction may reflect their traditionally poorer position in the labor market that may lower their expectations. Furthermore, although the job characteristics of men and women may be the same, their expectations of what their job should be like, or the reference points against which they compare, are different. Because men, on average, tend to earn more than women do, it is likely that men and women may aspire to different levels of reference income. McCue and Reed (1996) document significant reference point heterogeneities as well as different reservation wages between men and women. Long (1995) reports that a strong longing for financial well-being substantially increases males' earnings, whereas McGoldrick (1996) finds that women are unlikely to give up more with a view to gaining higher earnings. Regarding hours and effort requirements of jobs, two recent developments have been significant: changes in the extent to which workers' preferences are matched to employers' demands, and the intensification of work effort. First, while there have been no major increases in average weekly hours of workers, there has been an increase in the concentration of hours within households. In both Britain and the US, the weekly hours worked by dual-earner households have substantially risen since the early 1980s (Jacobs and Gerson 2001). Because employment opportunities within firms are normally constrained, and given that employers' and employees' preferences can fluctuate, some individuals may need to change jobs in order to attain their desired level of labor supply (Altonji and Paxson 1992, Stewart and Swaffield 1997, Euwals et al. 1998). It is well established that these labor market rigidities have a more negative impact on female workers because of the different set of constraints and occupational strategies they face, including childcare responsibilities and a desire for flexible work schedules (Bianchi 2000). 


\section{Concluding comments}

A closer and more rigorous examination of the dynamics of adjustment towards reference points in the context of labor markets has been long overdue. While previous studies have acknowledged the importance of aspirations and reference points in influencing workers' labor market behavior, there is very little empirical evidence on the dynamics of such an adjustment process. To the best of our knowledge, this is one of the first studies to model the adjustment process as an ESTAR process, a non-linear process that allows for the speed of adjustment to vary with the distance of workers' actual values from their reference points. The non-linear model, proposed here, has the additional advantage of capturing the potential asymmetry in individuals' responses depending on whether current values are below or above their reference values. Our results show that non-linear adjustment takes place only when actual values are below reference values. In contrast, when actual values are above reference values, there is no adjustment at all, linear or non-linear. Perhaps not surprisingly, workers with current wages or job satisfaction below their reference values will seek ways to change their current status, while workers whose current values are above their reference points will adopt a more risk-averse attitude towards changing their current status. In many respects, this is a similar prediction to that of efficiency wages models whereby efficiency wages deter risk-seeking behavior on the part of workers and deter labor mobility. Although the asymmetric adjustment in hours of work, implied by our findings, is perhaps less intuitive, it is still broadly consistent with a substantial volume of research in both the economics and sociological literature explaining hours constraints and over-employment. Thus, our analysis offers not only a novel and rigorous test of the dynamics of adjustment towards reference points, but also the importance of job satisfaction and other job attributes as determinants of labor market behavior. However, while we have established that the ESTAR model is superior to a linear model in characterizing the path of adjustment towards reference points, the novelty of our approach highlights the need for a detailed examination, in future research, of the performance of alternative 
non-linear models in characterizing the adaptation process. Given the sharp transitions from one regime to another, as our results for males suggest, a particularly fruitful avenue for future research would be also to investigate in more detail non-linearities within a Markov switching framework. Finally, empirical testing for the presence of non-linearities in the process of formation of reference points remains a largely unexplored area in the adaptation literature that we aim to explore in future work. 


\section{REFERENCES}

Akerlof, G., Rose, A.K., Yellen, J.L., 1988. Job switching and job satisfaction in the U.S. labor market. Brookings Papers on Economic Activity 2, 495-582.

Altonji, J., Paxson, C., 1992. Labor supply, hours constraints and job mobility. Journal of Human Resources 27, 256-278.

Bianchi, S.M., 2000. Maternal employment and time with children: dramatic change or surprising continuity? Demography 37, 401-414.

Brickman, P. Campbell, D., 1971. Hedonic relativism and planning the good society. In: Appley, M.H. (Ed.). Adaptation-level theory: A symposium. New York: Academic Press, 287-302.

Brickman, P., Coates, D., Janoff-Bulman, R., 1978. Lottery winners and accident victims: is happiness relative? Journal of Personality and Social Psychology 36, 917-927.

Burkhauser, R., Butrica, B., Daly, M., Lillard, D., 2001. The cross-national equivalent file: a product of cross-national research. In: Becker, I., Ott, N., Rolf, G. (Eds.). Soziale sicherung in einer dynamsichen gesellschaft (Social insurance in a dynamic society). Festschrift für Richard Hauser zum 65. Frankfurt/New York: Geburtstag, 354-376.

Clark, A.E., 1997. Job satisfaction and gender: Why are women so happy at work? Labour Economics 4, 341-372.

Clark, A.E., 2000. Is utility absolute or relative? Revue Economique 51, 459-471.

Clark, A.E., 2001. What really matters in a job? Hedonic measurement using quit data. Labour Economics 8, 223-242.

Clark, A.E., 2005. Your money or your life: Changing job quality in OECD countries. British Journal of Industrial Relations 43, 377-400.

Clark, A.E., Georgellis, Y., Sanfey, P., 1998. Job satisfaction, wage changes and quits: evidence from Germany. Research in Labor Economics 17, 95-121.

Clark, A.E., Oswald, A., 1996. Satisfaction and comparison income. Journal of Public Economics 61, 359-381.

Clark, A.E., Oswald, A., Warr, P., 1996. Is job satisfaction U-shaped in age? Journal of Occupational and Organizational Psychology 69, 57-81.

Dunn, L.F., 1996. Loss aversion and adaptation in the labor market: Empirical indifference functions and labor supply. Review of Economics and Statistics 78, 441-450.

Easterlin, R.A., 1995. Will raising the income of all increase the happiness of all? Journal of Economic Behavior and Organization 27, 35-47.

Easterlin, R.A., 2001. Income and happiness: Toward a unified theory. Economic Journal 111, 464484.

Easterlin, R.A., 2005. A puzzle for adaptive theory. Journal of Economic Behavior and Organization 56, 513-521.

Euwals, R., Melenberg, B., Van Soest, A., 1998. Testing the predictive value of subjective labour supply data. Journal of Applied Econometrics 13, 567-585.

Euwals, R., Van Soest, A., 1999. Desired and actual labour supply of unmarried men and women in the Netherlands. Labour Economics 6, 95-118.

Ferrer-I-Carbonell, A., 2005. Income and well-being: An empirical analysis of the comparison income effect. Journal of Public Economics 89, 997-1019.

Fiegenbaum, A., Hart, S., Schendel, D., 1995. Strategic reference point theory. Strategic Management Journal 10, 507-522.

Freeman, R.B., 1978. Job satisfaction as an economic variable. American Economic Review 68, $135-141$.

Granger, C., Terasvirta, T., 1993. Modelling non-linear economic relationships. Oxford University Press.

Green, F., Tsitsianis, N., 2005. An investigation of national trends in job satisfaction in Britain and Germany. British Journal of Industrial Relations 43, 401-429. 
Hamermesh, D.S., Pfann, G.A., 1996. Adjustment costs in factor demand. Journal of Economic Literature 34, 1264-1292.

Hamilton, J., 1989. A new approach to the economic analysis of non-stationary time series and the business cycle. Econometrica 57, 357-384.

Headey, B., Wearing, A., 1989. Personality, life events, and subjective well-being: Toward a dynamic equilibrium model. Journal of Personality and Social Psychology 57, 731-739.

Jacobs, J.A., Gerson, K., 2001. Overworked individuals or overworked families? Work and Occupations 28, 40-63.

Kahn, S.B., Lang, K., 1995. The causes of hours constraint: Evidence from Canada. Canadian Journal of Economics 18, 914-928.

Kahneman, D., and Tversky, A., 1979. Prospect theory: An analysis of decision under risk. Econometrica 47, 263-291.

Levy-Garboua, L., Montmarquette, C., 2004. Reported job satisfaction: What does it mean?' Journal of Socio-Economics 33, 135-151.

Lindenberg, S., 2001. Social rationality versus rational egoism. In: Turner, J. (Ed.). Handbook of Sociological Theory. New York: Kluwer Academic/Plenum, 635-668.

Long, J.E., 1995. The effects of tastes and motivation on individual income. Industrial and Labor Relations Review 48, 338-351.

Lucas, R., Clark, A.E., Georgellis, Y., Diener, E., 2003. Reexamining adaptation and the set point model of happiness: Reactions to changes in marital status. Journal of Personality and Social Psychology 84, 527-539.

Lykken, D., Tellegen, A., 1996. Happiness is a stochastic phenomenon. Psychological Science 7, 186-189.

McBride, M., 2001. Relative-income effects on subjective well-being in the cross-section. Journal of Economic Behavior and Organization 45, 251-278.

McCue, K., Reed, W.R., 1996. Married women's hours and participation revisited. Applied Economics 26, 277-281.

McGoldrick, K., 1996. Do women receive compensating wages for earnings uncertainty? Southern Economic Journal 62, 210-222.

Persky, J., Tam, M.Y., 1990. Local status and national social welfare. Journal of Regional Science 30, 229-238.

Rizzo, J., Zeckhauser, R., 2003. Reference incomes, loss aversion, and physician behavior. Review of Economics and Statistics 85, 909-922.

Solberg, E.C., Diener, E., Wirtz, D., Lucas, R., 2002. Wanting, having, and satisfaction: Examining the role of desire discrepancies in satisfaction with income. Journal of Personality and Social Psychology 83, 725-734.

Stewart, M.B., Swaffield, J., 1997. Constraints on the desired hours of work of British men. Economic Journal 107, 520-535.

Stutzer, A., 2004. The role of income aspirations in individual happiness. Journal of Economic Behavior and Organization 54, 89-109.

Terasvirta, T., 1994. Specification, estimation, and evaluation of smooth transition autoregressive models. Journal of the American Statistical Association 89, 208-218.

Terasvirta, T., Anderson, H.M., 1992. Characterizing nonlinearities in business cycles using smooth transition autoregressive models. Journal of Applied Econometrics 7, S1 19-139.

Van De Stadt, H., Kapteyn, A., Van de Geer, S., 1985. The relativity of utility: Evidence from panel data. Review of Economics and Statistics 67, 179-187.

Van Praag, B.M.S., 1971. The welfare function of income in Belgium: An empirical investigation. European Economic Review 2, 337-369.

Van Praag, B.M.S., Kapteyn, A., 1978. Further evidence on the individual welfare function of income: An empirical investigation in the Netherlands. European Economic Review 4, 3362 . 
Van Praag, B.M.S, Frijters, P., Ferrer-I-Carbonell, A., 2003. The anatomy of subjective well-being. Journal of Economic Behavior and Organization 51, 29-49. 
TABLE 1 - TESTS FOR NON-LINEARITIES

\begin{tabular}{|c|c|c|c|}
\hline MALES & & FEMALES & \\
\hline Job Satisfaction & & Job Satisfaction & \\
\hline Lag Length $-\mathrm{k}$ & 4 & Lag Length $-\mathrm{k}$ & 3 \\
\hline Delay Parameters $-\mathrm{d}$ & 1 & Delay Parameters - $\mathrm{d}$ & 1 \\
\hline$H_{0}: \beta_{2}{ }^{\prime}=\beta_{3}{ }^{\prime}=\beta_{4}{ }^{\prime}=0 .-p$ value & 0.004 & $H_{0}: \beta_{2}{ }^{\prime}=\beta_{3}{ }^{\prime}=\beta_{4}{ }^{\prime}=0 .-p$ value & 0.002 \\
\hline Ljung-Box $Q(1)$ statistic - $p$ value & 0.522 & Ljung-Box $Q(1)$ statistic - $p$ value & 0.401 \\
\hline Earnings & & Earnings & \\
\hline Lag Length $-\mathrm{k}$ & 5 & Lag Length $-\mathrm{k}$ & 4 \\
\hline Delay Parameters $-\mathrm{d}$ & 1 & Delay Parameters - d & 1 \\
\hline$H_{0}: \beta_{2}{ }^{\prime}=\beta_{3}{ }^{\prime}=\beta_{4}{ }^{\prime}=0 .-p$ value & 0.003 & $H_{0}: \beta_{2}{ }^{\prime}=\beta_{3}{ }^{\prime}=\beta_{4}{ }^{\prime}=0 .-p$ value & 0.002 \\
\hline $\begin{array}{l}\text { Ljung-Box } Q(1) \text { statistic - } p \text { value } \\
\text { Work Hours }\end{array}$ & 0.498 & $\begin{array}{l}\text { Ljung-Box } Q(1) \text { statistic - } p \text { value } \\
\text { Work Hours }\end{array}$ & 0.398 \\
\hline Lag Length $-\mathrm{k}$ & 7 & Lag Length $-\mathrm{k}$ & 6 \\
\hline Delay Parameters $-\mathrm{d}$ & 1 & Delay Parameters - d & 1 \\
\hline$H_{0}: \beta_{2}{ }^{\prime}=\beta_{3}{ }^{\prime}=\beta_{4}{ }^{\prime}=0 .-p$ value & 0.003 & $H_{0}: \beta_{2}{ }^{\prime}=\beta_{3}{ }^{\prime}=\beta_{4}{ }^{\prime}=0 .-p$ value & 0.002 \\
\hline Ljung-Box $Q(1)$ statistic - $p$ value & 0.497 & Ljung-Box $Q(1)$ statistic - $p$ value & 0.532 \\
\hline
\end{tabular}

Notes: The linearity test is a variable-deletion $\mathrm{F}$ test on the restriction applied to equation (5). P-values correspond to the test $H_{0}$ where the null is linearity. The Schwartz criterion is used to determine the lag length $k$ of the autoregressive process. $Q(1)$ refers to the $p$-value associated with the Ljung-Box $Q$ statistic for serial correlation among the residuals. 
TABLE 2 - SPECIFICATION OF NON-LineAR MODELS

\begin{tabular}{cc|cc}
\hline & MALES & \multicolumn{2}{|c}{ FEMALES } \\
\hline Job Satisfaction & 0.136 & Job Satisfaction & 0.157 \\
$H_{04}$ & $0.005 \ddagger$ & $H_{04}$ & $0.004 \ddagger$ \\
$H_{03}$ & $H_{03}$ & 0.168 \\
$H_{02}$ & 0.80 & $H_{02}$ & \\
Earnings & 0.154 & $H_{04}$ & 0.150 \\
$H_{04}$ & $0.004 \ddagger$ & $H_{03}$ & $0.004 \ddagger$ \\
$H_{03}$ & 0.127 & $H_{02}$ & 0.160 \\
$H_{02}$ & & Work Hours & 0.164 \\
Work Hours & 0.173 & $H_{04}$ & $0.002 \ddagger$ \\
$H_{04}$ & $0.003 \ddagger$ & $H_{03}$ & 0.139 \\
$H_{03}$ & 0.143 & $H_{02}$ & \\
$H_{02}$ & & & \\
\hline \hline
\end{tabular}

Notes

$\ddagger$ denotes the lowest $p$-value associated with the variable-deletion tests and therefore the determination of the relevant STAR model. The values of $\mathrm{k}$ (lag length) and $\mathrm{d}$ (delay parameters) are reported in Table 1. Type of model in all cases: ESTAR. 


\section{TABLE 3 -ESTIMATES OF THE ESTAR MODELS}

\begin{tabular}{|c|c|}
\hline MALES & FEMALES \\
\hline Job Satisfaction & Job Satisfaction \\
\hline$e_{t}=0.50+0.672 e_{t-1}+\left(0.84+0.792 e_{t-1}\right)$ & $e_{t}=0.45+0.800 e_{t-1}+\left(0.76+0.7801 e_{t-1}\right)$ \\
\hline $\begin{array}{llll}(0.16) & (0.30) & (0.32) & (0.33)\end{array}$ & $\begin{array}{llll}(0.11) & (0.05) & (0.24) & (0.24)\end{array}$ \\
\hline $\mathrm{x}\left[1-\exp \left\{-4.193\left(1 / \sigma^{2}(e)\right)\left(e_{t-1}-0.459\right)^{2}\right\}\right.$ & $\mathrm{x}\left\lceil 1-\exp \left\{-2.94\left(1 / \sigma^{2}(e)\right)\left(e_{t-1}-0.463\right)^{2}\right\}\right.$ \\
\hline$(1.02)$ & $(1.06)$ \\
\hline $\begin{array}{l}\mathrm{S}=0.362, \mathrm{Q}(1)=0.582, \operatorname{ARCH}(1)=0.170, \operatorname{NORM}(2)= \\
0.155, \mathrm{~S} / \mathrm{SL}=0.792\end{array}$ & $\begin{array}{l}\mathrm{S}=0.386, \mathrm{Q}(1)=0.491, \operatorname{ARCH}(1)=0.181, \operatorname{NORM}(2)= \\
0.154, \mathrm{~S} / \mathrm{SL}=0.721\end{array}$ \\
\hline Earnings & Earnings \\
\hline$e_{t}=0.70+0.720 e_{t-1}+\left(0.78+0.831 e_{t-1}\right)$ & $e_{t}=0.54+0.767 e_{t-1}+\left(0.81+0.790 e_{t-1}\right)$ \\
\hline $\begin{array}{llll}(0.13) & (0.25) & (0.30) & (0.32)\end{array}$ & $\begin{array}{llll}(0.10) & (0.05) & (0.28) & (0.20)\end{array}$ \\
\hline $\mathrm{x}\left[1-\exp \left\{-3.762\left(1 / \sigma^{2}(e)\right)\left(e_{t-1}-0.450\right)^{2}\right\}\right.$ & $\mathrm{x}\left[1-\exp \left\{-2.33\left(1 / \sigma^{2}(e)\right)\left(e_{t-1}-0.4488\right)^{2}\right\}\right.$ \\
\hline$(1.01)$ & $(0.21)$ \\
\hline $\begin{array}{l}\mathrm{S}=0.370, \mathrm{Q}(1)=0.683, \operatorname{ARCH}(1)=0.167, \operatorname{NORM}(2)= \\
0.182, \mathrm{~S} / \mathrm{SL}=0.844\end{array}$ & $\begin{array}{l}\mathrm{S}=0.395, \mathrm{Q}(1)=0.544, \operatorname{ARCH}(1)=0.180, \operatorname{NORM}(2)= \\
0.170, \mathrm{~S} / \mathrm{SL}=0.721\end{array}$ \\
\hline Work Hours & Work Hours \\
\hline$e_{t}=0.74+0.714 e_{t-1}+\left(0.74+0.826 e_{t-1}\right)$ & $e_{t}=0.55+0.731 e_{t-1}+\left(0.79+0.753 e_{t-1}\right)$ \\
\hline $\begin{array}{llll}(0.16) & (0.25) & (0.30) & (0.31)\end{array}$ & $\begin{array}{llll}(0.10) & (0.08) & (0.32) & (0.24)\end{array}$ \\
\hline $\mathrm{x}\left[1-\exp \left\{-3.642\left(1 / \sigma^{2}(e)\right)\left(e_{t-1}-0.444\right)^{2}\right\}\right.$ & $\mathrm{x}\left[1-\exp \left\{-2.27\left(1 / \sigma^{2}(e)\right)\left(e_{t-1}-0.4502\right)^{2}\right\}\right]$ \\
\hline$(1.06)$ & $(1.02)$ \\
\hline $\begin{array}{l}\mathrm{S}=0.422, \mathrm{Q}(1)=0.532, \operatorname{ARCH}(1)=0.172, \operatorname{NORM}(2)= \\
0.191, \mathrm{~S} / \mathrm{SL}=0.762\end{array}$ & $\begin{array}{l}\mathrm{S}=0.401, \mathrm{Q}(1)=0.478, \operatorname{ARCH}(1)=0.173, \operatorname{NORM}(2)= \\
0.163, \mathrm{~S} / \mathrm{SL}=0.798\end{array}$ \\
\hline
\end{tabular}

Notes

Values under regression coefficients are standard errors. $Q(1)$ is the p-value for first order serial correlation (Ljung-Box $Q$ statistic). $A R C H(1)$ is the $p$-value for the first order autoregressive conditional heteroscedasticity (Engle F-test). NORM(2) is the $p$-value for the JacqueBera normality test. $S / S L$ is the ratio of the standard errors for the non-linear and linear models. 
TABLE A1 - EARNINGS EQUATIONS

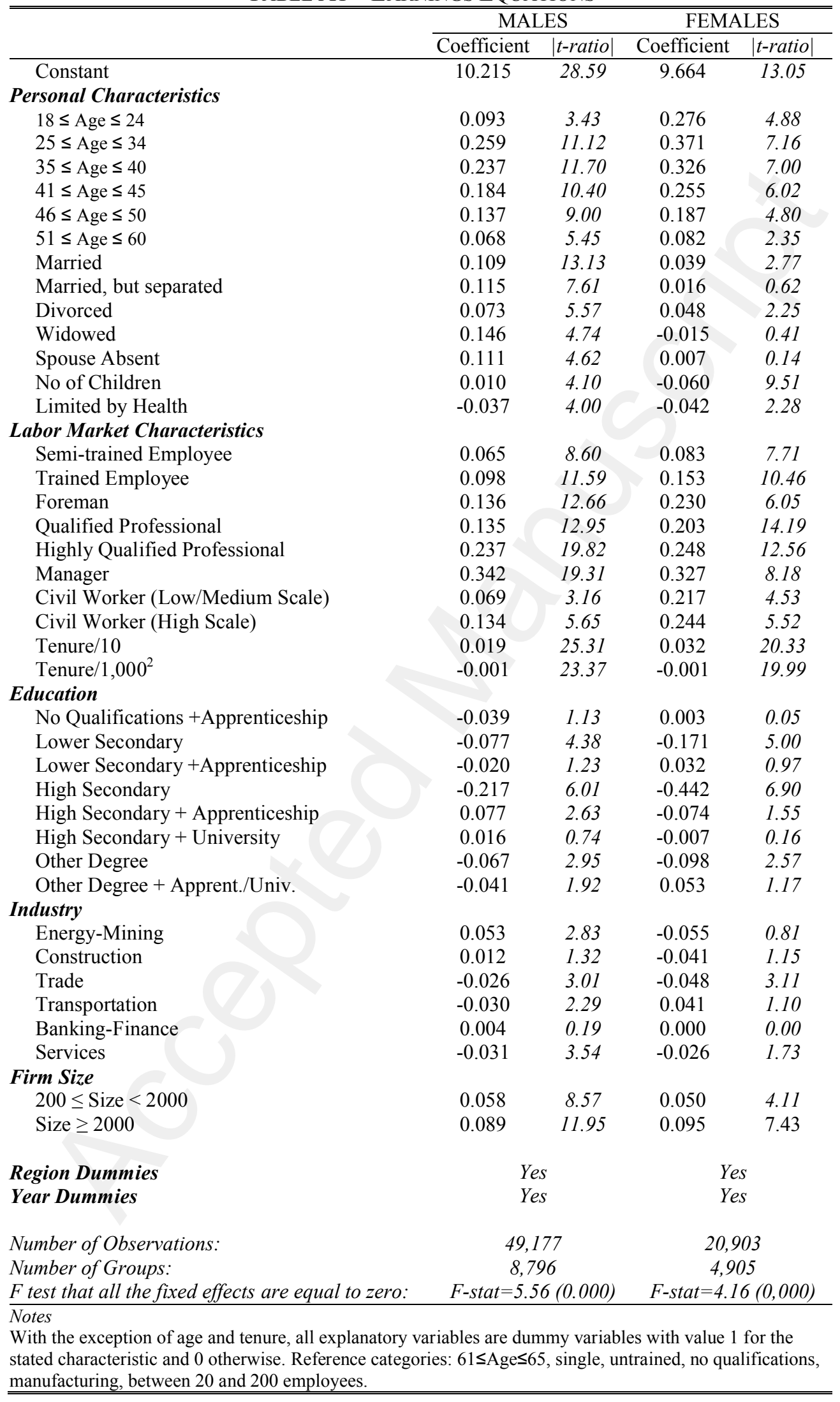


TABLE A2 - JOB SATISFACTION EQUATIONS

\begin{tabular}{|c|c|c|c|c|}
\hline & \multicolumn{2}{|c|}{ MALES } & \multicolumn{2}{|c|}{ FEMALES } \\
\hline & Coefficient & $\mid$ t-ratio $\mid$ & Coefficient & $\mid t$-ratio $\mid$ \\
\hline Constant & 21.468 & 10.09 & 18.472 & 8.59 \\
\hline Log (Wages) & 0.112 & 3.91 & 0.343 & 1.06 \\
\hline Log (Reference Income) & -0.936 & 7.39 & -0.692 & 5.30 \\
\hline Log (Hours) & -0.109 & 1.98 & -0.230 & 0.30 \\
\hline \multicolumn{5}{|l|}{ Preferences for Hours of Work } \\
\hline Actual $>$ Desired (Over-employed) & -0.341 & 6.99 & -0.440 & 7.20 \\
\hline Actual < Desired (Under-employed) & -0.211 & 3.48 & -0.314 & 2.13 \\
\hline \multicolumn{5}{|l|}{ Personal Characteristics } \\
\hline $18 \leq$ Age $\leq 24$ & 0.364 & 2.13 & 0.338 & 0.61 \\
\hline $25 \leq$ Age $\leq 34$ & 0.270 & 4.70 & 0.295 & 1.25 \\
\hline $35 \leq$ Age $\leq 40$ & 0.216 & 5.72 & 0.272 & 1.56 \\
\hline $41 \leq$ Age $\leq 45$ & 0.209 & 5.45 & 0.295 & 2.00 \\
\hline $46 \leq$ Age $\leq 50$ & 0.442 & 4.60 & 0.344 & 1.57 \\
\hline $51 \leq$ Age $\leq 60$ & 0.517 & 3.18 & 0.421 & 0.28 \\
\hline Married & 0.135 & 3.54 & -0.115 & 2.11 \\
\hline Limited by health & -0.361 & 6.79 & -0.411 & 4.37 \\
\hline \multicolumn{5}{|l|}{ Labor Market Characteristics } \\
\hline Semi-trained Employee & 0.218 & 4.76 & 0.154 & 2.66 \\
\hline Trained Employee & 0.412 & 7.73 & 0.323 & 3.88 \\
\hline Foreman & 0.569 & 8.27 & 0.879 & 4.34 \\
\hline Qualified Professional & 0.674 & 10.08 & 0.573 & 6.56 \\
\hline Highly Qualified Professional & 0.902 & 11.89 & 0.799 & 6.86 \\
\hline Manager & 0.949 & 11.54 & 0.799 & 3.68 \\
\hline Civil Worker (Low/Medium Scale) & 0.152 & 1.20 & 0.844 & 3.36 \\
\hline Civil Worker (High Scale) & 0.668 & 4.80 & 0.936 & 4.43 \\
\hline \multicolumn{5}{|l|}{ Education } \\
\hline No Qualifications +Apprenticeship & -0.299 & 1.51 & -0.489 & 1.59 \\
\hline Lower Secondary & -0.240 & 2.36 & -0.051 & 0.29 \\
\hline Lower Secondary + Apprenticeship & -0.146 & 1.58 & 0.310 & 1.83 \\
\hline High Secondary & -0.275 & 1.29 & -0.701 & 2.06 \\
\hline High Secondary + Apprenticeship & -0.006 & 0.04 & 0.142 & 0.58 \\
\hline High Secondary + University & 0.045 & 0.36 & -0.245 & 1.13 \\
\hline Other Degree & -0.137 & 1.04 & -0.419 & 2.13 \\
\hline Other Degree + Apprent./Univ. & -0.179 & 1.47 & 0.043 & 0.19 \\
\hline \multicolumn{5}{|l|}{ Industry } \\
\hline Energy-Mining & 0.109 & 1.01 & 0.017 & 0.05 \\
\hline Construction & 0.042 & 0.83 & 0.248 & 1.34 \\
\hline Trade & -0.042 & 0.84 & 0.070 & 0.87 \\
\hline Transportation & -0.007 & 0.09 & 0.791 & 4.10 \\
\hline Banking-Finance & 0.092 & 0.74 & 0.412 & 2.50 \\
\hline Services & -0.044 & 0.85 & 0.271 & 3.49 \\
\hline \multicolumn{5}{|l|}{ Firm Size } \\
\hline $200 \leq$ Size $<2000$ & 0.124 & 3.03 & 0.192 & 3.02 \\
\hline Size $\geq 2000$ & 0.288 & 6.10 & 0.376 & 5.40 \\
\hline Region Dummies & \multicolumn{2}{|c|}{ Yes } & \multicolumn{2}{|c|}{ Yes } \\
\hline Year Dummies & \multicolumn{2}{|c|}{ Yes } & \multicolumn{2}{|c|}{ Yes } \\
\hline Number of Observations: & \multicolumn{2}{|c|}{49,177} & \multicolumn{2}{|c|}{20,903} \\
\hline Number of Groups: & \multicolumn{2}{|c|}{8,796} & \multicolumn{2}{|c|}{4,905} \\
\hline F test that all the fixed effects are equal to zero: & \multicolumn{2}{|c|}{$F$-stat $=4.47(0.000)$} & \multicolumn{2}{|c|}{$F$-stat $=3.38(0.000)$} \\
\hline
\end{tabular}


Figure 1: Earnings - actual and reference values

\section{MALES}

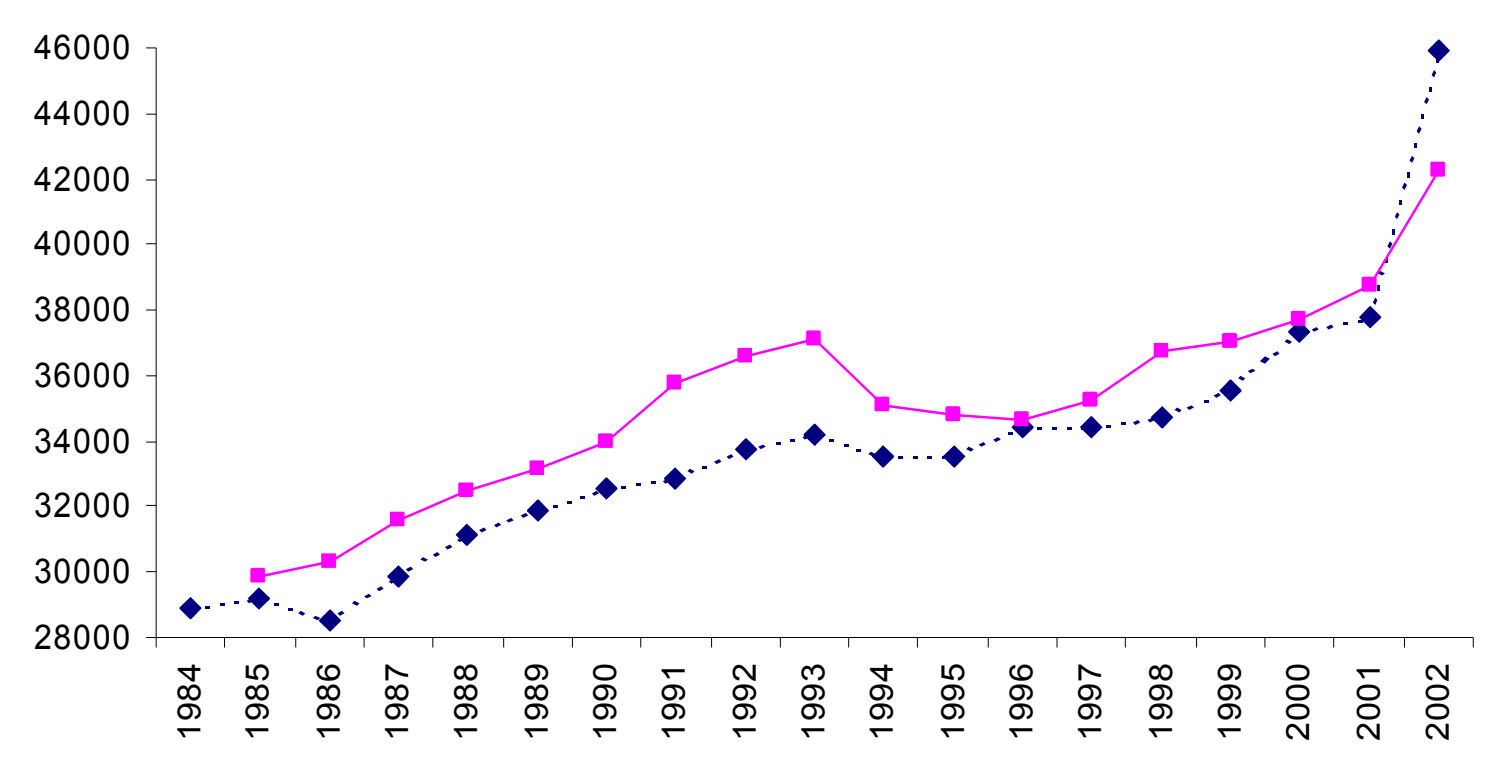

\section{FEMALES}

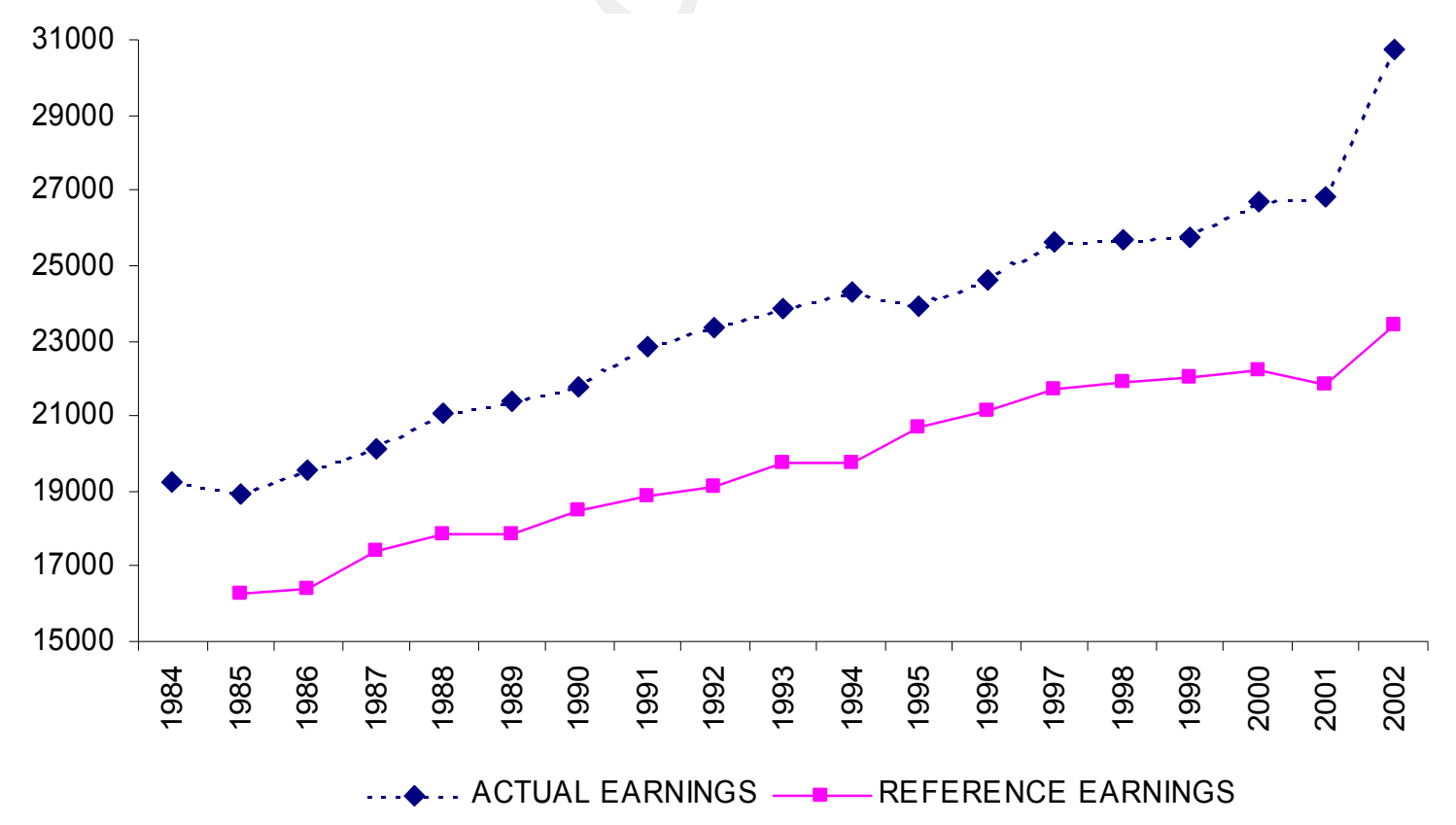


Figure 2: Job satisfaction - actual and reference values

\section{MALES}

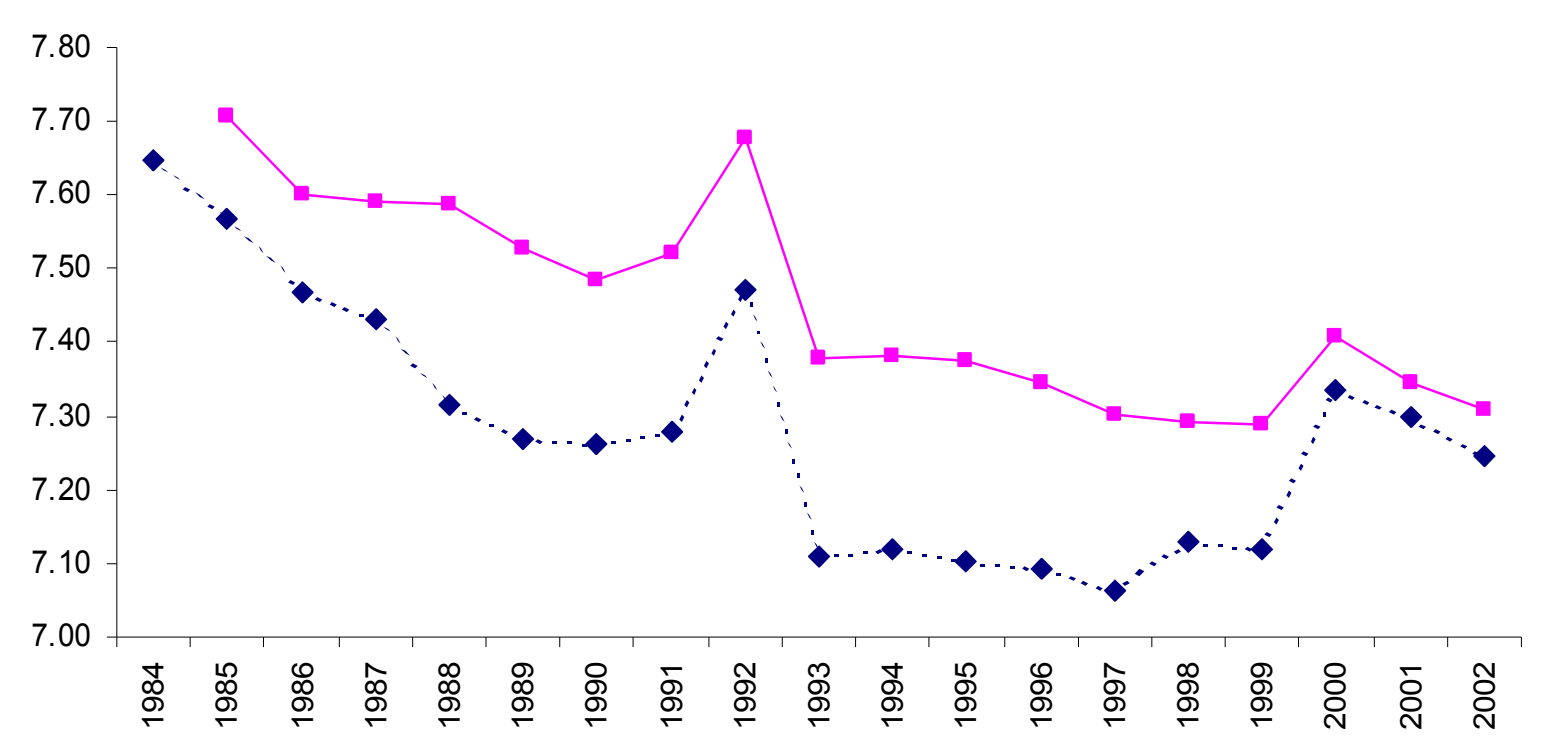

FEMALES

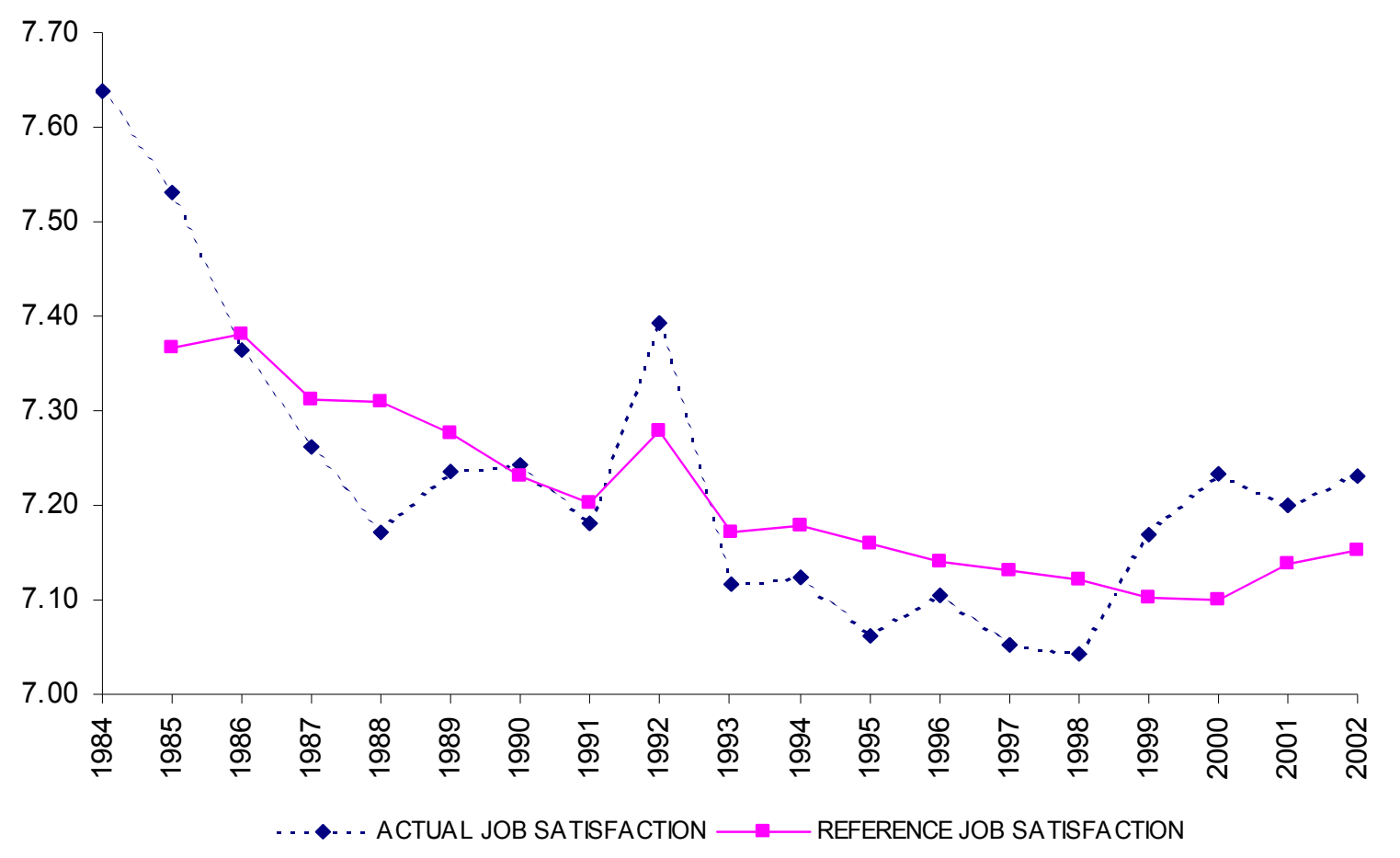


Figure 3: Work hours - actual and reference values

\section{MALES}

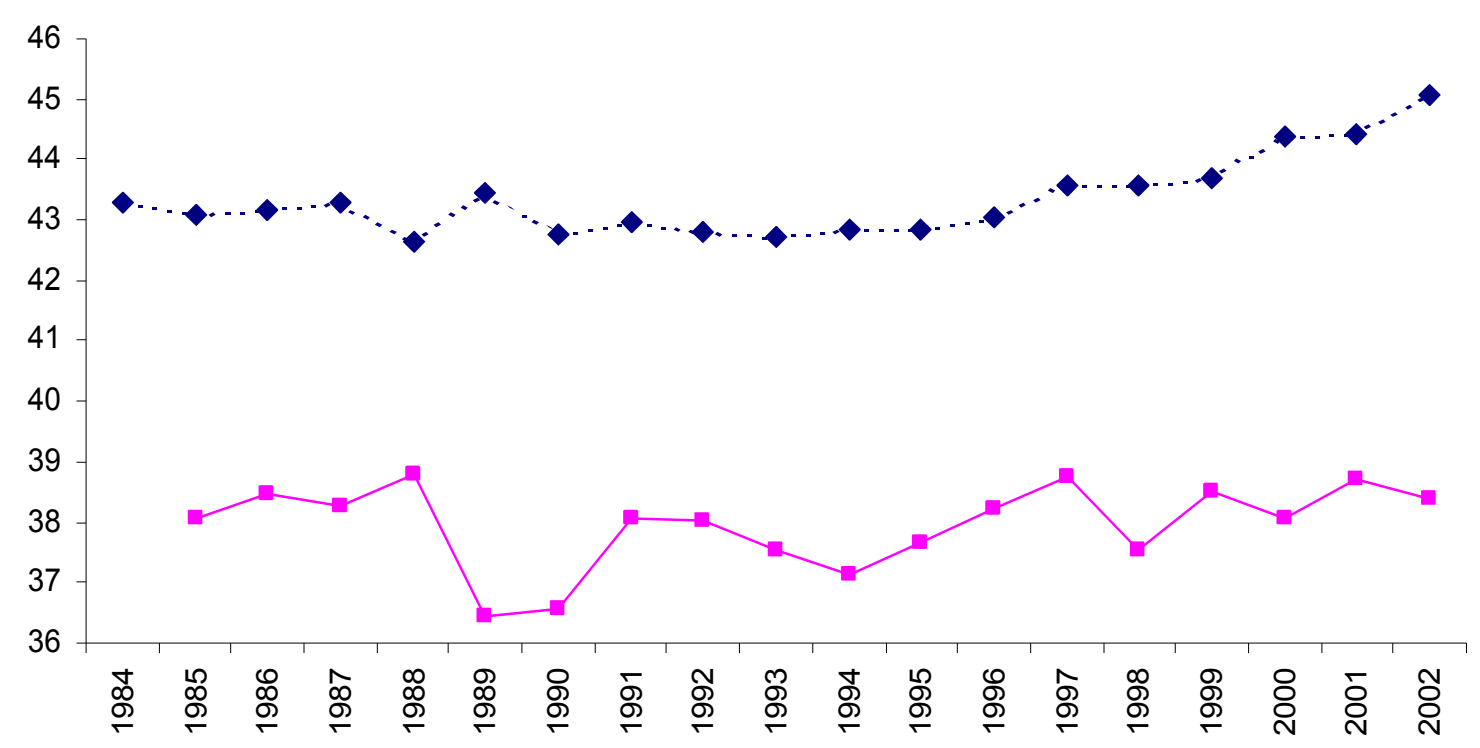

FEMALES

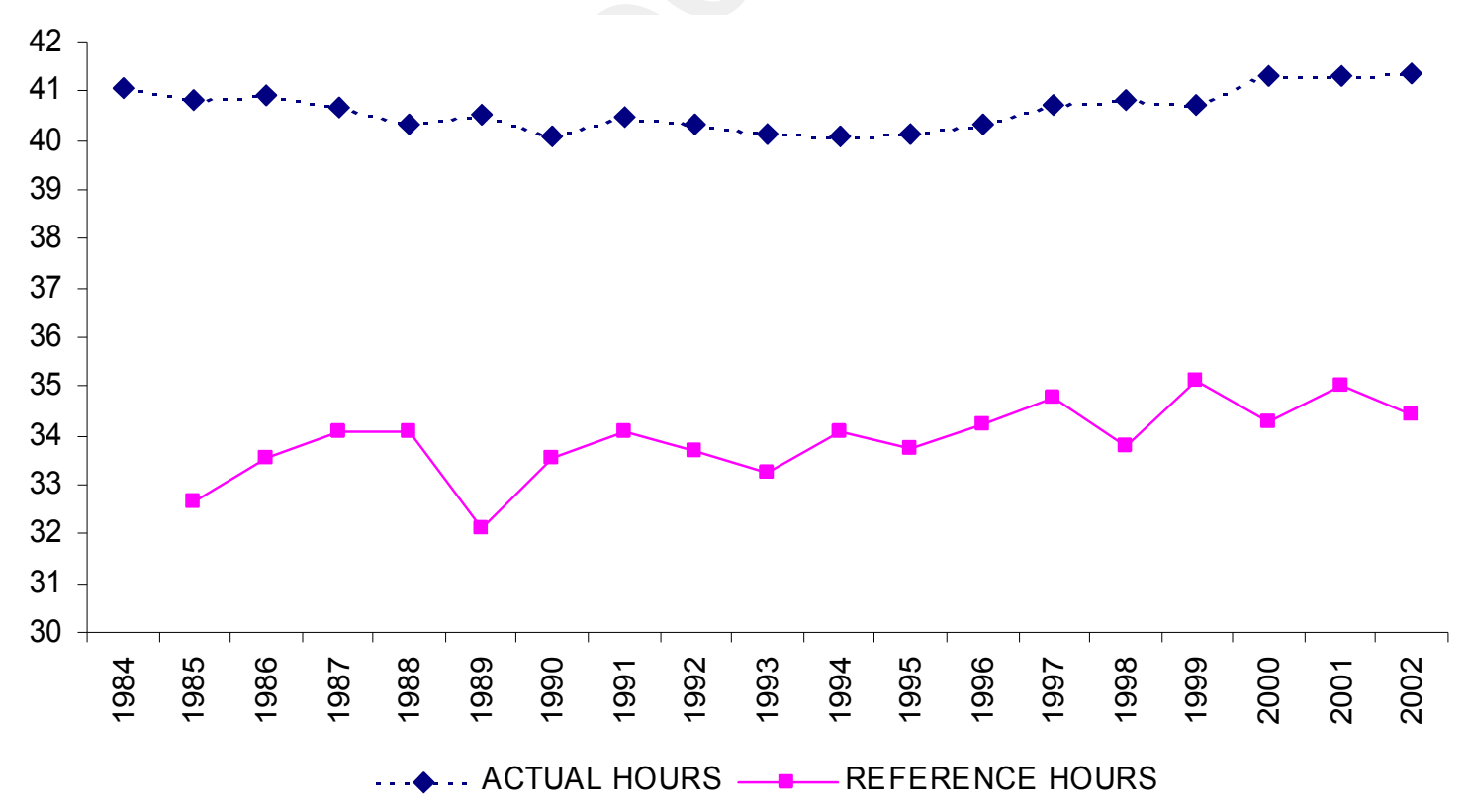

